\title{
Overview of NASA Earth Observing Systems Terra and Aqua moderate resolution imaging spectroradiometer instrument calibration algorithms and on-orbit performance
}

\author{
Xiaoxiong (Jack) Xiong, ${ }^{a}$ Brian N. Wenny, ${ }^{b}$ and William L. Barnes ${ }^{e}$ \\ Sciences and Exploration Directorate, NASA/GSFC, Greenbelt, MD 20771 \\ Xiaoxiong. Xiong-lanasagov \\ ${ }^{b}$ Science Systems and Applications, Inc, 10210 Greenbelt Road, Lanham, MD 20706 \\ Brian Wenny ossaihq.com \\ Joint Center for Eath Systems Technology University of Maryland Baltimore County \\ 5523 Research Park Drive, Baltimore, MD 21228 \\ wlbarnes 9 avitc.com
}

\begin{abstract}
Since launch, the Terra and Aqua moderate resolution imaging spectroradiometer (MODIS) instruments have successfully operated on-obbit for more than 9 and 6.5 years, respectively. MODIS, a key instrument for the NASA's Earth Observing System (EOS) missions, was designed to make continuous observations for studies of Earth's land, ocean, and atmospheric properties and to extend existing data records from heritage earth-observing sensors. In addition to frequent global coverage, MODIS observations are made in 36 spectral bands, covering both solar reflective and thernal enissive spectral regions. Nearly 40 data products are routinely generated from MODIS observations and publicly distributed for a broad range of applications. Both instruments have produced an unprecedented amount of data in support of the science community. As a general reference for understanding sensor operation and calibration, and thus science data quality, we provide an overview of the MODIS instruments and their pre-launch calibration and characterization, and describe their on-orbit calibration algorithms and performance. On-orbit restilts from both Terra and Aqua MODIS radiometric, spectral, and spatial calibration are discussed. Currently, both instruments, including their on-board calibration devices, are healthy and are expected to continue operation for several years to come.
\end{abstract}

Keywords: MODIS, calibration, radiometric, spectral, spatial, on-board calibrators. 